\title{
The Influence of Solvent on Complex Formation of Crown Ether with Tetraphenylphosphonium Chloride
}

\author{
Atri Deo Tripathi
}

Department of Chemistry, College of Engineering, Teerthankar Mahaveer University, Moradabad-244001, India

\begin{abstract}
The host guest interactions of crown ether (18-C-6) with tetraphenylphosphonium chloride (TPPC) were studied in different solvents at $303.15 \mathrm{~K}$. The values of reaction enthalpies, $\Delta H^{\circ}$, and equilibrium constant, $K$, have been calculated and the results show that solvation of tetraphenylphosphonium ion $\left(\mathrm{Ph}_{4} \mathrm{P}^{+}\right)$is not very important. Because the cavity of the 18-C-6 is too small to completely accommodate large $\mathrm{Ph}_{4} \mathrm{P}^{+}$ion. Thus, the interactions between the cation and the oxygen donor atoms of the ligand decrease, the large cation is surrounded by large organic moieties which interact more strongly with the organic environment and therefore it will not have tendency to form complex in nonaqueous solvents.
\end{abstract}

Keywords: Crown ether, tetraphenylphosphonium chloride, micro calorimeter, equilibrium constant, solvation.

\section{INTRODUCTION}

Earlier we have reported heat capacities of TPPC with methanol, ethanol, acetonitrile and water and the results obtained have been discussed from the viewpoint of ion-solvent and solute-solute interactions between the components [1]. In the present programme, crown ether and TPPC behavior in various solvents have been undertaken.

Mixtures of crown ethers (host) with tetraphenylphosphonium chloride in water, methanol, ethanol, 1- propanol, 1-butanol, acetone, acetonitrile and 2-propanol are of considerable interest from the viewpoint of specific interactions between these components. It has been found that the intramolecular cavity size of the macro cyclic ligands strongly affects the stability constant of the complexes. In the present case the tetraphenylphosphonium ion $\left(\mathrm{Ph}_{4} \mathrm{P}^{+}\right)$is a very large ion which is highly polarizable [1] and is not solvated in water and therefore it does not require desolvation before complexation with crown ether. A literature survey revealed that extensive studies concerning the properties of these systems have not been made. In the present study, measurements of reaction enthalpies and equilibrium constants of crown ether with tetraphenylphosphonium ion in water, methanol, ethanol, 1-propanol, 2- propanol, butanol, acetone and acetonitrile solutions were carried out at $303.15 \mathrm{~K}$ and the results obtained have been interpreted in terms of interactions between crown ether and TPPC in above-mentioned solvents in this paper.

*Address correspondence to this author at the Department of Chemistry, College of Engineering, Teerthankar Mahaveer University, Moradabad-244001, India; Tel: +919458444596; E-mail: atrideo@rediffmail.com

\section{EXPERIMENTAL}

The macrocyclic ligand 18-crown-6 (18-C-6; Merck) was used without further purification. Tetraphenylphosphonium chloride (Janssen chimica) was dried in vacuo at $50^{\circ} \mathrm{C}$ for 24 hours and used without further purification since NMR spectroscopy detected no impurity except water. Double distilled and deionised water was used. Ethanol (USSR Company, best quality) was distilled from freshly heated $\mathrm{CaO}$, dried with metal calcium and fractionally distilled at $78.3^{\circ} \mathrm{C}$. Methanol (BDH, AR) was dried by activated molecular sieves. Chromatographic analysis showed no organic impurities and the water content did not exceed $0.01 \%$. 1-propanol, 2- propanol, butanol, and acetonitrile (> $99.59 \mathrm{~mol} \%$, of purity) were used without further purification. All compounds were activated over molecular sieve $4 \mathrm{~A}^{0}$.

Experiments have been done by batch method on C-80 calorimeter [2]; the calorimeter consists of a reference and experimental vessel. These are surrounded by two symmetrical thermal flux meters composed of thermocouples in series. The whole assembly is kept in an aluminium block and allowed to reach thermal equilibrium. If there is any heat liberated or absorbed in the experimental vessel during mixing of crown ether and TPPC, it leads to change in temperature which is allowed and this persists till same temperature is attained in both the vessels. The experimental cell has two chambers separated by tilting lid. The samples are separately introduced into the vessel by equilibrium. The mixing is performed by inverting the whole calorimeter by $180^{\circ} \mathrm{C}$. The amount of heat, $q$ evolved during an experiment can be calculated by determining the area under the curve obtained during the experiment. The concentration of

(C) 2015 Lifescience Global 
18-C-6 was $0.5 \mathrm{M}$ and $0.1 \mathrm{M}$ for tetraphenylphosphonium chloride throughout the experiment.

\section{Calculation of $\mathrm{K}$ and $\Delta \mathrm{H}^{0}$}

If the initial concentrations of crown ether and TPPC are $a_{0}$ and $b_{0}$ respectively and $V_{1}$ and $V_{2}$ are their volumes then the concentrations of crown ether, a and that of $\mathrm{Ph}_{4} \mathrm{P}^{+}, \mathrm{b}$, in the solution are given by

$a=\frac{a_{0} v_{1}}{v_{1}+v_{2}}=\frac{a_{0} v_{1}}{V}$

$b=\frac{b_{0} v_{2}}{v_{1}+v_{2}}=\frac{b_{0} v_{2}}{V}$

And we have

$a=\frac{x}{(a-x)(b-x)}=K$

Where $x$ is the concentration of the inclusion complex and $\mathrm{K}$ is the equilibrium constant for the reaction. For low concentrations of $\mathrm{a}$ and $\mathrm{b}$ we find with good approximation that

$\frac{x}{(a-x)}=b K$

or $x=\frac{a b}{(a+b+1 / K)}$

Now $\Delta H^{0}$ and $q$ are related by the equation

$$
\begin{aligned}
& q=\frac{\Delta H^{\circ} v}{(a-x)(\boldsymbol{b}-x)}=\frac{a b}{(a+b+1 / K)} \\
& =\frac{1000 q}{v}+\frac{a+b}{a+b}+\frac{1000 q}{v K a b}=\Delta H^{0}
\end{aligned}
$$

or

$\frac{1000 q}{v} \frac{(a+b)}{a b}=\Delta H^{0}-\frac{1000 q}{v K a b}$

Now if we plot the experimental quantities $\frac{1000 q}{v} \frac{(a+b)}{a b}$ against $\frac{1000 q}{v a b}$ then the intercept should be equal to $\Delta H^{0}$ and $K$ can be calculated from the slope ( $K=-1 /$ slope). Figures 1 and 2 give such plots from which we have been able to calculate $\Delta H^{0}$ and $K$ for the reactions. It can be seen from Figure 1 that if $\Delta$ $\mathrm{H}^{0} \mathrm{~K}$ is very large then intercept is very small and can not be determined very accurately. For this purpose we have developed this method of nonlinear least squaring i.e. we start with approximate values of $\Delta H^{0}$ and $K$ and write

$q=Q 0+A D K+B D+\Delta H^{0}$

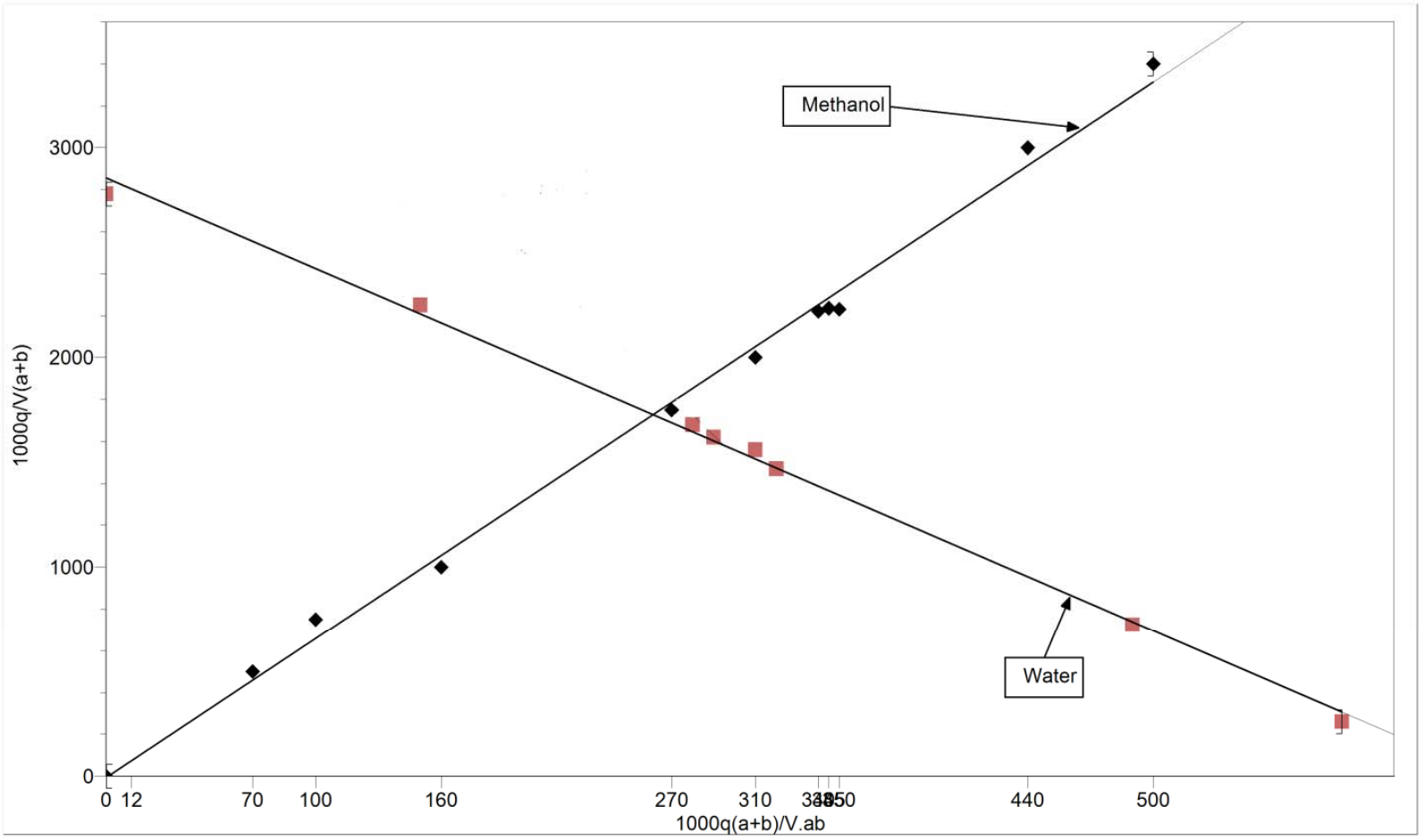

Figure 1: Crown ether with TPPC in methanol and water at $303.15 \mathrm{~K}$. 


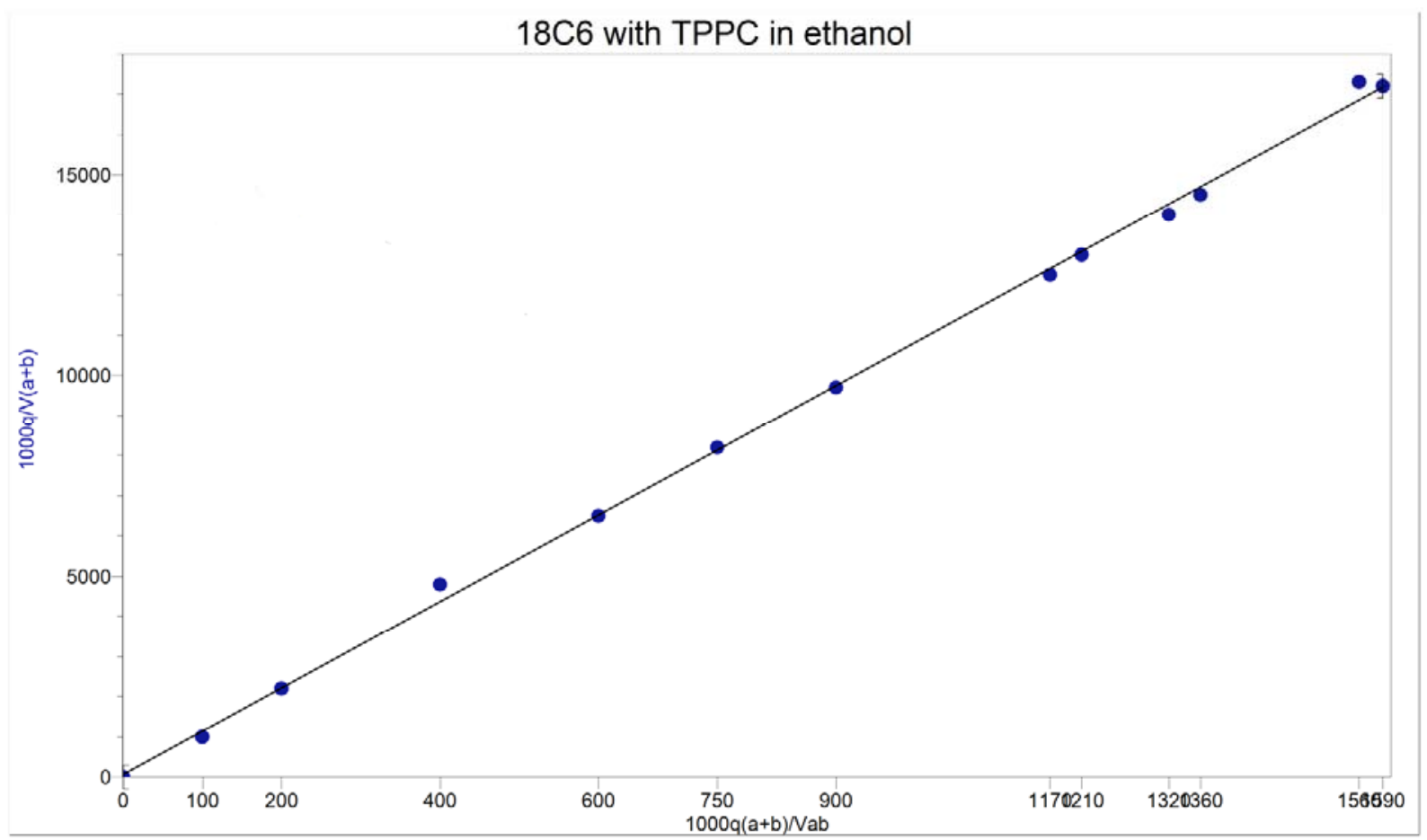

Figure 2: Crown ether with TPPC in ethanol at 303.15K.

The values of $D K$ and $D \Delta H^{0}$ are determined. The ilnteraction continues till the desired accuracy.

\section{RESULTS AND DISCUSSION}

We have studied the system $18 \mathrm{C} 6$ and tetraphenylphosphonium chloride in water, methanol, ethanol, 1-propanol,2- propanol, butanol-1, acetone and acetonitrile at $303.15 \mathrm{~K}$. The values of $\Delta \mathrm{H}^{0}$ and $\mathrm{K}$ are given in Table 1. The plots according to equation 1 , for the system $18 \mathrm{C} 6$ and tetraphenylphosphonium chloride in water and methanol at $303.15 \mathrm{~K}$ are shown in Figure 1 and in ethanol shown in Figure 2.

We have found that in water $\Delta H^{0}=1000 \mathrm{~J}$ and $K=1.5$. On the other hand in other solvents $K$ has small value. This can be interpreted that actually there is no complexation in these solvents. The results are a bit surprising as for most of the alkali metal ions there is stronger complexation in the non-aqueous solvent [3]. This has been understood in terms of strong solvation of alkali metal ions in water compared to other organic solvents. In the present case the $\mathrm{Ph}_{4} \mathrm{P}^{+}$ion is a very large ion and is not solvated in water and therefore it does not require desolvation before complexation with crown ether. However, due to the large size of the ion it is expected that both $\mathrm{K}$ and $\Delta \mathrm{H}^{0}$ will be small. This is in agreement with the experimental results. On the other hand, the large cation is surrounded by large organic moieties which interact more strongly with the organic environment and therefore it will not have

Table 1: Reaction Enthalpies, $\Delta H^{0}$ and Equilibrium Constant $K$ for Complexation of 18-C-6 with Tetra Phenyl Phosphonium Chloride in Different Solvents at 303.15 K

\begin{tabular}{|c|c|c|c|}
\hline Solvents & $-\boldsymbol{\Delta} \boldsymbol{H}^{\mathbf{0}} / \mathbf{J} / \mathbf{m o l}$ & $\boldsymbol{K}$ /itre $\mathrm{mol}^{-1}$ & $\boldsymbol{K} \boldsymbol{H}^{\mathbf{0}} / \mathbf{J}$. litre $\mathbf{m o l}^{-2}$ \\
\hline \hline Methanol & 500 & 3.5 & 1750 \\
\hline Water & 1000 & 1.5 & 1500 \\
\hline Ethanol & 512 & 3.6 & 1843.2 \\
\hline 1-Propanol & 550 & 3.7 & 2035 \\
\hline 1-Butanol & 580 & 3.8 & 2204 \\
\hline Acetone & 600 & 3.3 & 1980 \\
\hline Acetonitrile & 400 & 4.1 & 1640 \\
\hline 2-Propanol & 400 & 3.2 & 1720 \\
\hline
\end{tabular}


tendency to form complex in non-aqueous solvents. It can be seen from the table that $\mathrm{K} \Delta \mathrm{H}_{0}$ values for all the solvents are nearly the same. This can be explained by the fact that solvation of such a large cation is not very important. There is, however, little information about the interactions between crown ethers and solvent molecules in the liquid phase [4-6]. The cavity of the $18 \mathrm{C} 6$ is too small to completely accommodate large $\mathrm{Ph}_{4} \mathrm{P}^{+}$ion. Thus, the interactions between the cation and the oxygen donor atoms of the ligand decrease. The observed $\log \mathrm{K}$ is small; this can be attributed to the fact that there is formation of weak complexes between 18-C-6 and tetraphenylphosphonium chloride in different solvents.

\section{ACKNOWLEDGEMENT}

Author is extremely grateful to Professor D.V.S. Jain, Dept. Of Chemistry, Punjab University Chandigarh for constant encouragement and Professor N.K. Joshi, Principal, College of Engineering, Teerthankar Mahaveer University, Moradabad for providing laboratory facilities during course of this investigation.

\section{REFERENCES}

[1] Tripathi AD. Heat capacities of tetra phenyl phosphonium chloride with ethanol, methanol, acetonitrile and water. Fluid Phase Equilibria 2010; 293: 205-8.

http://dx.doi.org/10.1016/j.fluid.2010.03.017

[2] Pathak G, Tripathi AD, Pradhan S. The excess molar enthalpies of mixing of 1,1,2,2-tetrachloroethane with ace tone, n-dibutyl ether, acetonitrile and dimethylsulphoxide. Thermochim Acta 1992; 197: 329-33. http://dx.doi.org/10.1016/0040-6031(92)85031-P

[3] Nath J, Tripathi AD. Binary systems of 1,1,2,2 tetrachloroethane with benzene, toluene, $p$-xylene, acetone and cyclohexane. 1. Excess volumes, ultrasonic velocities, and adiabatic compre ssibilities at 298.15 and $308.15 \mathrm{~K}$. J Chem Engg Data 1983; 28: 263-6. http://dx.doi.org/10.1021/je00032a038

[4] Izatt RM, Pawlak K, Bradshaw JS, Bruening RL. Thermodynamic and kinetic data for macrocycle interactions with cations and anions. Chem Rev 1991; 91: 1721-2085. http://dx.doi.org/10.1021/cr00008a003

[5] Buschmann HJ. The influence of acetonitrile on complex formation of crown ethers containing different donor atoms. $J$ Sol Chem 1988; 17: 277-86.

http://dx.doi.org/10.1007/BF00646180

[6] Boer JAA de, Reinhoudt DN, Harkema S, van Hummel GJ, Jong FJ de. Thermodynamic constants of complexes of crown ethers and uncharged molecules and $x$-ray structure of the 18-crown-6. (MeNO2)2 complex. J Am Chem Soc 1982; 104: 4073-6. http://dx.doi.org/10.1021/ja00379a006 